\title{
Notícia: Carolina Martuscelli Bori, Analista do Comportamento, Pesquisadora
}

\author{
João Claudio Todorov ${ }^{1}$ \\ Universidade de Brasília e Universidade Católica de Goiás \\ News: Carolina Martuscelli Bori, \\ Behavior Analyst, Researcher
}

\begin{abstract}
Carolina era uma pessoa contida, muito preocupada com a exatidão do que falava. Não tinha uma fluência verbal muito grande, talvez por essa preocupação em ser exata e falar as coisas corretamente. Transmitia por isso uma impressão de seriedade, de preocupação com a precisão e a solidez do que afirmava. (Cunha, 1998, p. 50)
\end{abstract}

Seu segredo pessoal dependeu sempre de atributos humanos que não são dados a ser generalizados para qualquer pessoa, tais como altruísmo, serenidade, conhecimento meditado, simplicidade e comedimento, razões pelas quais veio a ocupar lugar muito especial na comunidade científica brasileira. (Ab'Saber, 1998, p. 35)

De compleição franzina e delicada, de voz mansa e suave, de comportamento cordial e educado, de repente Carolina Bori se transfigura. Ela se altera, se agita, eleva a voz. Quem a vê nessas ocasiões, não a reconhece. Aliás, acho que não a conhece! Porque quem a conhece (e, por isso, a admira), sabe que, nessas ocasiões, Carolina Bori está simplesmente extravasando com vigor e firmeza, um dos traços mais marcantes de sua fascinante personalidade: a defesa intransigente de seus princípios e de suas idéias. Ela não arreda pé de suas convicções. A menos, é claro, que seja convencida disso. De qualquer forma, ultrapassada a batalha verbal, quer tenha convencido ou tenha sido convencida, ela volta imediatamente à voz mansa e suave, como se nada houvesse acontecido de diferente. (Freire-Maia, 1998, p. 190)

Faleceu em São Paulo, em 4 de outubro deste ano, Carolina Martuscelli Bori. Formada em pedagogia em uma das primeiras turmas da Universidade de São Paulo, dedicouse desde o início ao ensino de psicologia para vários cursos da USP. Em 1952 defendeu sua dissertação de mestrado nos Estados Unidos, na New School for Social Research de Nova Iorque. Em 1953 já ensinava Psicologia Experimental no primeiro ano do Curso de Filosofia da Faculdade de Filosofia, Ciências e Letras da USP.

Carolina Martuscelli Bori teve uma longa carreira de sucessos como professora, pesquisadora e administradora, sempre dedicada às suas duas grandes paixões: a psicologia, enquanto ciência e profissão, e a ciência de modo geral. Segundo Aziz Ab'Saber, que a conheceu quando jovem,

1 Endereço: Universidade Católica de Goiás, Curso de Mestrado em Psicologia, Av. Universitária 1.440, Setor Universitário, Goiânia, GO, Brasil 74605-010. E-mail: todorov@unb.br desde cedo impressionava pela beleza e pela argumentação ao se levantar para falar no auditório do prédio da Caetano de Campos, na Praça da República (Ab’Saber, 1998). Sua capacidade de expressar indignação era uma marca registrada. Sempre cortês e gentil com todos, era firme e exigente com seus pares e seus alunos.

Era uma mulher de princípios. Na noite de 14 de agosto último Dona Carolina foi uma de minhas entrevistadoras para um vídeo sobre a história da análise do comportamento no Brasil. Para minha surpresa, a primeira pergunta não foi sobre psicologia; foi sobre o que senti ao tomar a decisão de deixar a USP - Ribeirão Preto em 1973 e voltar para a UnB. Uma pergunta que demorou 31 anos para ser feita. Terminada a entrevista, Dona Carolina voltou ao assunto para dizer que, apesar de opiniões em contrário, a decisão que tomou em outubro de 1965, liderando o pedido de demissão coletiva dos professores da UnB em protesto pela demissão arbitrária de 15 colegas, era a coisa a ser feita naquelas condições. Era uma questão de princípios.

Deixou ex-alunos espalhados por todo o Brasil, e mais alguns no exterior. Licenciada em pedagogia pela USP e mestre em ciências sociais nos Estados Unidos, foi professora da USP, primeiro como assistente da Profa. Anita Cabral na Faculdade de Filosofia Ciência e Letras, depois no Instituto de Psicologia. Sem deixar a USP, viajou muito ajudando na implantação e desenvolvimento de outros centros, como a Faculdade de Filosofia, Ciência e Letras de Rio Claro, a Universidade de Brasília, onde implantou o Curso de Psicologia (1963-1965) e era membro do Conselho Diretor (desde 1990), a Universidade Federal de São Carlos, onde foi Diretora do Centro de Educação e Ciências Humanas (1976-1979) e Professora Visitante (1982-1983), o campus de Ribeirão Preto da USP, a Universidade Federal da Bahia, e muitos outros. Todos os cursos de psicologia no Brasil foram influenciados de maneira direta ou indireta pelo trabalho de Carolina Bori.

Seu poder de liderança foi muito bem exercido em várias organizações. Nos anos 50 e 60 foi presidente da Associação Brasileira de Psicólogos e atuou decisivamente para a aprovação da lei que criou os cursos de psicologia e regulamentou a profissão no país (1962), levando à implantação do Conselho Federal e Conselhos Regionais de Psicologia. Em reconhecimento, o CRP/07 (São Paulo) deu-lhe o registro de número 1. No MEC foram décadas de colaboração, da comissão que providenciou o registro de psicólogos que exerciam a profissão antes da aprovação da lei, aos comitês e comissões de especialistas, na CAPES, na SESU, no INEP. Colaborou com Anísio Teixeira e Darcy Ribeiro na 
implantação do Centro Brasileiro de Pesquisas Educacionais e no Centro Regional de Pesquisas Educacionais de São Paulo. Ocupou todos os cargos de direção da SBPC, sendo a primeira mulher a ocupar a presidência; continuava muito ativa como membro do conselho na qualidade de presidente de honra. Também foi presidente da Sociedade Brasileira de Psicologia (SBP), da Sociedade de Psicologia de São Paulo, e da Associação Nacional de Pesquisa e Pós-Graduação em Psicologia (ANPEPP). Era Diretora Científica do Núcleo de Pesquisas sobre o Ensino Superior da USP.

Em 1998 o Instituto de Psicologia da USP homenageou sua Professora Emérita com um número especial da revista Psicologia USP, Volume 9, Número 1, "Carolina Bori, Psicologia e Ciência no Brasil", com depoimentos e artigos de dezenas de pessoas que a conheceram e com ela trabalharam, entre eles Aziz Nacib Ab'Saber, Maria Isaura Pereira de Queiroz, Francisco Mauro Salzano, José Goldemberg, Aldo Malavasi, Ennio Candotti, Gilberto Velho, Oscar Sala, Ademar Freire-Maia e Eduardo Moacyr Krieger. Também foi homenageada pelas Universidades de Brasília e Federal de São Carlos com os títulos de Doutor Honoris Causa.

Há uma extensa bibliografia sobre o papel de Carolina Bori na implantação do curso de psicologia da UnB e no desenvolvimento da análise do comportamento no Brasil (Keller, 1968, 1975, 1987a, 1987b, 1996).

\section{Referências}

Ab'Saber, A. (1998). Carolina Bori: A essência de um perfil. Psicologia USP, 9(1), 35-36.

Cunha, W. H. A. (1998). Carolina Martuscelli Bori e a psicologia na USP. Psicologia USP, 9(1), 49-60.

Freire-Maia, A. (1998). Carolina SBPC Bori. Psicologia USP, 9(1), 189-190.

Keller, F. S. (1968). Goodbye teacher... Journal of the Applied Behavior Analysis, 1, 1-13.

Keller, F. S. (1975). On my experience in Brazil. Boletim de Psicologia, 26, 105-110.

Keller, F. S. (1987a). Itens de um fichário. Psicologia: Teoria e Pesquisa, 3(2), 84-91.

Keller, F. S. (1987b). O nascer de um departamento. Psicologia: Teoria e Pesquisa, 3(3), 198-205.

Keller, F. S. (1996). Report on the Brasília Plan. Psicologia: Teoria e Pesquisa, 12(3), 193-197. 